\title{
Sodium Carbonate
}

National Cancer Institute

\section{Source}

National Cancer Institute. Sodium Carbonate. NCI Thesaurus. Code C47721.

The disodium salt of carbonic acid with alkalinizing property. When dissolved in water, sodium carbonate forms carbonic acid and sodium hydroxide. As a strong base, sodium hydroxide neutralizes gastric acid thereby acting as an antacid. 